\title{
Serum and milk concentrations of enrofloxacin in cows intramammarily treated with a new enrofloxacin-polymorph")
}

\author{
ISMAEL MARTÍNEZ-CORTÉS, LILIA GUTIERREZ*, GRACIELA TAPIA**, \\ LUIS OCAMPO*, HECTOR SUMANO*
}

\begin{abstract}
Departamento de Medicina y Zootecnia para Rumiantes, *Departamento de Fisiología y Farmacología, ${ }^{* *}$ Departamento de Genética y Bioestadística, Facultad de Medicina Veterinaria y Zootecnia, Universidad Nacional Autónoma de México, Av. Universidad 3000, Delegación Coyoacán, México 04510
\end{abstract}

Martínez-Cortés I., Gutierrez L., Tapia G., Ocampo L., Sumano H.

Serum and milk concentrations of enrofloxacin in cows intramammarily treated with a new enrofloxacin-polymorph

Summary

The success rate in treatment against Staphylococcus aureus mastitis with antibacterial drugs is marginal. Low antibacterial drug concentrations in the mammary tissue is part of the reason for this failure. Enrofloxacin has only been administered on few occasions through the intramammary route i.e., combined with gentamicin in an undisclosed vehicle or dose. A new solvate form of enrofloxacin (enrofloxacin hydrochloride-dihydrate (enro-C)) prepared as $1.5 \%$ suspension $\mathrm{pH} 5.5$ was tested in a field mastitis outbreak due to coagulase-negative S. aureus (CNS) in F1 (Holstein/Zebu) cows aged 5-8 years destined to be culled. Enro-C was administered intramammarily daily ( $300 \mathrm{mg} /$ infected quarter) for 8 days both to healthy and mastitic cows; milk and serum enro- $C$ concentrations were determined on days 1 and 8 . Maximum serum concentration $\left(C_{\mathrm{MAX}}\right)$ values were similar in both groups $(9.4$ to $10.7 \mu \mathrm{g} / \mathrm{mL})$. The area under the moment curve (AUMC) for enrofloxacin increased only by $11 \%$ in healthy cows and by $10 \%$ in infected cows from day 1 to day 8 , a fact that suggests little accumulation with this dose regime. Peak concentrations in milk ranged from 18.5 to $19.8 \mu \mathrm{g} / \mathrm{mL}$ on day 1 and from 20.2 to $22 \mu \mathrm{g} / \mathrm{mL}$ on day 8 . Cure rates on day 21 after treatment were $75 \%$ (12 out of 16 cows) or 69.4\% (26 out of 36 glands). Somatic cell counts and California mastitis test showed a positive trend in cured animals. Uniquely high milk enrofloxacin and ciprofloxacin concentrations were obtained after intramammary administration of enro-C. These concentrations seem effective for treating CNS mastitis. The feasibility of incorporating this experimental pharmaceutical preparation of enrofloxacin is discussed.

Keywords: intramammary-administration, cow, enrofloxacin, enro-C, mastitis, Staphylococcus aureus

Therapeutic success rates in treating subclinical and clinical mastitis by Staphylococcus aureus are marginal. Sub-effective concentrations in milk and/or insufficient contact time with the affected mammary tissue are common causes for antibiotic failure (26). While parenteral enrofloxacin preparations are not usually recommended to treat bovine mastitis due to Staphylococcus aureus, high milk concentrations of enrofloxacin and its main metabolite (ciprofloxacin) are reached and maintained after parenteral administration (14). However, it must be considered that actual antibacterial activity can be partly impaired by the presence of milk and inflammatory secre-

1) The authors are grateful for the financial support given by the Project UNAM/ PAPIIT IT200714. tions (10). It is then likely to consider that higher concentrations of enrofloxacin and ciprofloxacin can improve clinical efficacy. This has been suggested when treating mastitis due to Staphylococcus aureus in sheep by means of parenteral administration of enrofloxacin (2). Intramammary administration may overcome the problem of insufficient concentrations of enrofloxacin in mammary tissue. However, this administration route is not recommended for standard preparations of enrofloxacin. A thorough search of the available literature revealed that enrofloxacin has been administered through the intramammary route on only few occasions i.e., combined with gentamicin in an undisclosed vehicle or dose (15). However, to the best of our knowledge, no commercial preparations 
for this route exist in most countries, and the available products for parenteral administration have a $\mathrm{pH}$ at or above 10.4; a fact that makes intramammary administration of the drug rather unadvisable (28). However, a new recrystallized enrofloxacin polymorphic form, enrofloxacin hydrochloride-dihydrate (enro-C) (19), has shown higher water solubility than the parent compound and a superior bioavailability than reference enrofloxacin in broiler chicken (12). As a 1.5\% suspension, enro- $\mathrm{C}$ exhibits a $\mathrm{pH}$ of 5.5 , and it does not irritate the mammary gland when intramammarily administered (17). Thus, a study to quantify milk and serum enrofloxacin and ciprofloxacin concentrations after intramammary administration of $300 \mathrm{mg}$ of $1.5 \%$ enro- $\mathrm{C}$ aqueous suspension to cows was conducted. The efficacy against chronic Staphylococcus aureus mastitis was also assessed in a field outbreak.

\section{Material and methods}

Animals. All procedures were approved by the Institutional Committee for Research, Care and Use of Experimental Animals of the National Autonomous University of Mexico (UNAM), and conducted according to the Mexican Official Regulation NOM-062-ZOO-20 (http://dof.gob.mx/ nota_detalle.php? codigo $=762506 \&$ fecha $=22 / 08 / 2001$ ). Accordingly, all cows were slaughtered once the experiment was finished. This trial was carried out in Martínez de la Torre, Veracruz, a town in the Mexican tropic (20.0667 longitude; 97.05 latitude), in a dual-purpose dairy farm with F1 (50\% Holstein-50\% Zebu) cows in milk (mean production, $13.8 \mathrm{~L} /$ day) and mean weight of $625 \pm 23.5 \mathrm{~kg}$. Thirty-one cows from the herd were found infected with coagulasenegative Staphylococcus aureus (CNS). Intramammary infection (IMI) due to Staphylococcus sp. was regarded as chronic in these animals after repeated pathogen identification, as shown in Table 1, where other relevant features are also presented. None of the cows included in this trial were treated with an antibacterial drug for the current infection and had had their last antibacterial treatment at least a month ago. Chosen cows were divided by simple randomization through computer-generated random numbers, into two groups: 16 cows (16 glands infected) were treated with enro-C (Mi-Tx), and 15 cows (15 infected glands) were left untreated as controls (Mi-C). A third group of 12 cows was also treated with enro-C; these animals had no previous

Tab. 1. Characteristics (mean \pm SD and ranges) of the F1 $(50 \%$ Holstein $-50 \%$ Zebu) dual-purpose cows included in this trial

\begin{tabular}{|l|c|c|c|c|c|}
\hline \multicolumn{1}{|c|}{ Group } & Age (years) & $\begin{array}{c}\text { Lactation } \\
\text { number }\end{array}$ & Days in milk & $\begin{array}{c}\text { Individual milk } \\
\text { production }(\mathrm{kg})\end{array}$ & $\begin{array}{c}\text { Previous } \\
\text { mastitis cases* }\end{array}$ \\
\hline $\begin{array}{l}\text { Mi-Tx } \\
\text { (16 cows) }\end{array}$ & $\begin{array}{c}6.3 \pm 1.0 \\
(5-8)\end{array}$ & $4.3 \pm 1.0$ & $174 \pm 16$ & $2088 \pm 152$ & $\begin{array}{c}4.2 \pm 1.4 \\
(3-6)\end{array}$ \\
$\begin{array}{l}\text { Mi-C } \\
\text { (15 cows) }\end{array}$ & $\begin{array}{c}6.3 \pm 1.3 \\
(5-8)\end{array}$ & $4.3 \pm 1.3$ & $168 \pm 19$ & $2010 \pm 187$ & $\begin{array}{c}4.6 \pm 1.3 \\
(2-7)\end{array}$ \\
$\begin{array}{l}\text { Ni-Tx } \\
\text { (12 cows) }\end{array}$ & $\begin{array}{c}6.6 \pm 1.1 \\
(5-8)\end{array}$ & $4.6 \pm 1.3$ & $178 \pm 20$ & $2848 \pm 210$ & $\begin{array}{c}0.5 \pm 0.5 \\
(0-1)\end{array}$ \\
\hline
\end{tabular}

Explanations: * Diagnosed as Staphylococcus aureus IMI during the last lactation period; $\mathrm{Mi}-\mathrm{Tx}-\mathrm{S}$. aureus-infected, enro-C-treated; $\mathrm{Mi}-\mathrm{C}-\mathrm{S}$. aureus-infected, untreated; Ni-Tx - non-infected, enro-C-treated. history of Staphylococcus aureus IMI (Ni-Tx). Each group was relocated in different grounds, at least $1 \mathrm{~km}$ apart from each other, and were handled and milked in different settings to avoid cross-contamination.

Treatments. A batch of re-crystallized enrofloxacin was prepared as reported in Patent 472715 (Instituto Mexicano de la Protección Industrial, Mexico). This process yields enrofloxacin hydrochloride-dihydrate. Enrofloxacin was purchased from Globe Chemicals (Mexico City) with $99.97 \%$ purity. Enrofloxacin hydrochloride suspension ( $1.5 \%$ base) was prepared by slowly adding weighed amounts of polyvinylpyrrolidone K-30 and sodium chloride to a mixture of polypropylene glycol and cold injectable water with continuous stirring until complete dissolution. Then, enrofloxacin hydrochloride-dihydrate was added to the suspension, with stirring until complete dispersion; $\mathrm{pH}$ was adjusted to 5.5 with diluted hydrochloric acid, adding water to the final volume. The suspension was filtered through a $0.22-\mu \mathrm{m}$ pore membrane to yield a sterile, yellowish, transparent, particle-free liquid.

After the cows had been milked under aseptic conditions, the udder was washed, and each teat was cleaned thoroughly with a warm chlorhexidine-based antiseptic solution (Tetramast ${ }^{\circledR}$ Brovel, Mexico); teats were dried and the meatus was wiped with an alcohol-infused pad. Then, $300 \mathrm{mg}$ of enro-C per affected quarter were deposited midway into the teat with a $20-\mathrm{mL}$ intramammary, softplastic tip syringe, without massaging the gland. This procedure was repeated daily for 8 days in all treated cows regardless of age, days in milking period, milk production, and individual mastitis history.

Sampling. Pharmacokinetic data with a single dose of $300 \mathrm{mg} /$ cow was obtained from 8 cows in the Mi-Tx group and 8 cows in the Ni-Tx group. Serial blood samples were obtained by direct jugular vein puncture with a Vacutainer kit and 20-gauge needles (10 mL/sample), at $0.25,0.5,1$, $2,4,6,8,10,12$, and $24 \mathrm{~h}$ on day 1 and on day 8 of treatment $(168.25,168.5,169,170,174,176,178,180,182$ and $192 \mathrm{~h}$ ). Serum was recovered by centrifugation at $3000 \mathrm{rpm}$ for $15 \mathrm{~min}$, labeled, and frozen at $-20^{\circ} \mathrm{C}$ until analyzed. Milk samples were also obtained 2, 8, and $24 \mathrm{~h}$ after the first treatment, the last two sampling times coinciding with established milking times. Samplings were repeated on day 8 of enro-C intramammary treatment.

Bacteriological diagnosis. Additional milk samples $(10 \mathrm{~mL})$ were collected in sterile test tubes and immediately transported to the laboratory for microbiological analysis at $3-4^{\circ} \mathrm{C}$. Each sample was vortexed for $5 \mathrm{~min}$; then, $30 \mu \mathrm{L}$ of inoculant was spread in blood and on MacConkey agar plates and incubated under aerobic conditions at $37^{\circ} \mathrm{C}$ for $24-48 \mathrm{~h}$ (1). Colonies were classified according to morphological and biochemical characteristics, including Gram stain, catalase and coagulase activity, thermonuclease production, lysostaphin sensitivity, and anaerobic fermentation (glucose and mannitol) in accordance 
with established protocols (4). Samples were processed in triplicate.

Two additional samples were collected for the California mastitis test (CMT) and for somatic cell count (SCC) by an electronic cell counter (DeLaval DCC ${ }^{\circledR}$, Sweden). Bacteriological diagnosis, CMT, and SCC were repeated 14 and 21 days after the eight-day treatment scheme with enro-C, to assess whether or not a bacteriological cure was attained.

Cows included in this trial had at least four previous diagnoses of IMI due to Staphylococcus sp. in the current lactation cycle. Intramammary infection was defined as positive when Staphylococcus spp. was isolated and quantified as $\geq 30 \mathrm{CFU} / 30 \mu \mathrm{L}$ of inoculum in at least 2 out of 3 replicates (National Mastitis Council. Research Committee Report. http://nmconline.org/docs/InterpretBactResults.pdf (1987)). Cure criterion was the absence of the pathogen in two consecutive milk samplings, 14 and 21 days after the last treatment. Table 2 shows the biochemical tests identifying the mastitis causative microorganism as coagulasenegative Staphylococcus aureus.

Chromatographic enrofloxacin and ciprofloxacin determination. Enrofloxacin and ciprofloxacin determination in milk and serum samples was based on an HPLC method (13). Briefly, each sample was added with $1 \mathrm{~mL}$ of methylene chloride and centrifuged for $5 \mathrm{~min}$ at 10,000 rpm. Aqueous phase was discarded and organic phase was evaporated. Residues were reconstituted in the acetonitrile: methanol: water (17: 3: 80) mobile phase with phosphoric acid $(4 \% \mathrm{v} / \mathrm{v})$ and trimethylamine $(4 \% \mathrm{v} / \mathrm{v})$. The aqueous extract was analyzed by high-performance liquid chromatography (HPLC) with fluorometric detection at $\lambda$ ex $=278 \mathrm{~nm}$ and $\lambda \mathrm{em}=460 \mathrm{~nm}$. A Jasco XLC (LC-2000Plus ${ }^{\circledR}$ JASCO Benelux B. V., de Meern, Netherlands) HPLC system with a Symmetry- $\mathrm{C}_{18}$ column $(4.6 \mathrm{~mm} \times 100$ $\mathrm{mm}, 3.5 \mu \mathrm{m}$; Waters) was used. Injection volume was $50 \mu \mathrm{L}$ and flow was $0.6 \mathrm{~mL} / \mathrm{min}$. Data were analyzed with the EASYCHROME 2.0 software. Sarafloxacin hydrochloride was included as internal standard. The standard calibration curve was obtained by injecting five-level concentrations ranging from 0.05 to $20 \mu \mathrm{g} / \mathrm{mL}$ and measuring the peak areas of the chromatograms. The recovery percentages ranged from 95 to $104 \%$, with a maximum of $9 \%$ standard deviation. The lowest possible standard on the calibration curve was accepted as the limit of quantitation (LOQ). LOQ for enrofloxacin and ciprofloxacin in plasma was found to be $0.1 \mu \mathrm{g} / \mathrm{ml}$. LOQ for enrofloxacin and ciprofloxacin in milk was found to be $0.2 \mu \mathrm{g} / \mathrm{ml}$.

The following pharmacokinetic variables were calculated with the Microsoft Excel (C) 2013 Microsoft, USA) and WinNonlin (WinNonlin ${ }^{\circledR}$ Princeton, NJ, USA) software: absorption half-life $\left(\mathrm{T}^{1} 12_{\mathrm{ab}}\right)$; elimination half-life $\left(\mathrm{T}^{1} 1 / 2 \beta\right)$; maximum serum concentration $\left(\mathrm{C}_{\mathrm{MAX}}\right)$; time to achieve $\mathrm{C}_{\mathrm{MAX}}\left(\mathrm{T}_{\mathrm{MAX}}\right)$; area under the curve by the trapezoidal method (AUCt); area under the moment curve from zero to $\infty$ with extrapolation to the terminal phase (AUMC); mean residence time (MRT).

Statistical methods. Milk data are reported as mean and SD. Enrofloxacin and ciprofloxacin kinetic profiles were analyzed by ANOVA of repeated measurements. Posttreatment data for the presence of $S$. aureus in Mi-Tx and
Tab. 2. Biochemical features used to identify coagulase-negative Staphylococcus aureus in this study trial

\begin{tabular}{|l|c|}
\hline \multicolumn{1}{|c|}{ Test } & Response \\
\hline Catalase activity & $4+$ \\
\hline Coagulase production & - \\
\hline Thermonuclease production & + \\
Lysostaphin sensitivity & + \\
\hline Anaerobic utilization of glucose & + \\
Mannitol & + \\
\hline
\end{tabular}

Mi-C cows, California scores, and SCC on days 14 and 21 were also recorded. CMT and SCC data were analyzed by ANOVA for repeated measurements to determine differences between baseline and post-treatment values due to treatment.

Serum pharmacokinetic parameters for enrofloxacin and ciprofloxacin in Mi-Tx and Ni-Tx cows, and on days 1 and 8 of treatment, were compared using TTOST (two $t$-tests of single tail) with $\delta$-values not higher than $10 \% ; P<0.05$ was considered as significant. Post-treatment response in Mi-Tx and $\mathrm{Mi}-\mathrm{C}$ cows, with two possible responses (positive or negative), was assessed with the generalized linear model:

Where

$$
g\left(E\left(Y_{i}\right)\right)=g\left(\mu_{i}\right)=x_{i}^{\prime} \beta
$$

$\mu_{i}=\left(E\left(Y_{i}\right)\right)$ is a linear function relating the response means of linear predictor $x_{i}^{\prime} \beta$

$x_{i}^{\prime}$ is the vector of independent variables for the $i$-th observation, and

$\beta$ is the estimable regression parameters vector

$Y$ component is independent and has a binomial probability distribution, since only two possible responses exist ( $i=$ either positive or negative).

Test potency was determined with the GPower software (Buchner, A.; Erdfelder, E. and Faul, F. (1997) How to Use G*Power. URL:http://www.psycho.uniduesseldorf.de/aap/ projects/-gpower/how to use gpower.html (Last consulted July, 2015)). All other statistical analyses were performed with the Statistical Package for the Social Sciences (SPSS) for Windows, Version 20 (IBM, Mexico City) (Insurgentes Sur 933, piso 1. México, 03810.mexico@pass.mx).

\section{Results and discussion}

Table 3 shows the characteristics of the cows in the three groups, the number of glands and cows treated, CMT and SCC values before and after treatment, and the rate of bacteriological cure on days 14 and 21 after treatment for Mi-Tx and Mi-C cows. Cure rate, SCC, and CMT mean values show significant differences due to treatment $(\mathrm{P}=0.001)$. A $75 \%$ cure rate was attained (12 out of 16 cows), which represent $69.4 \%$ cured glands (25 out of 36 ). A G*Power analysis of these results showed a potency of 0.99 . The mastitis cure rates, the values of CMT and the SCC were all noticeably reduced after treatment with enro-C.

Figures 1 and 2 show mean \pm SD for ciprofloxacin and enrofloxacin serum concentrations on days 1 and 8 in Mi-Tx and Ni-Tx cows, respectively. Serum pharmacokinetics for enrofloxacin and ciprofloxacin in 
Tab. 3. Groups formed: Mi-Tx - Staphylococcus aureus-infected, enro-C-treated; Mi-C - S. aureus-infected, untreated; Ni-Tx - non-infected, enro-C-treated. California mastitis test (CMT) and somatic cell count (SCC) before and after treatment are shown, as well as the percent rate of bacteriological cure on days 14 and 21 in Mi-Tx and Mi-C cows

\begin{tabular}{|c|c|c|c|c|c|c|c|}
\hline \multirow{3}{*}{ Group } & \multirow{3}{*}{$\begin{array}{l}\text { No of cows } \\
\text { (glands) } \\
\text { infected }\end{array}$} & \multicolumn{2}{|c|}{ Before treatment* } & \multicolumn{2}{|c|}{ After treatment* } & \multirow{2}{*}{\multicolumn{2}{|c|}{$\begin{array}{c}\text { Bacteriological cure (\%) } \\
\text { Day }\end{array}$}} \\
\hline & & Mean CMT & Mean SCC & Mean CMT & Mean SCC & & \\
\hline & & scare & $(\times 1000$ cells $/ \mathrm{mL})$ & score & ( $\times 1000$ cells $/ \mathrm{mL})$ & 14 & 21 \\
\hline Mi-Tx & 16 & $2.75 \pm 0.44$ & $2212.5 \pm 650$ & $1.31 \pm 0.47$ & $209.8 \pm 75$ & $\begin{array}{c}75 \\
(12 / 16)\end{array}$ & $\begin{array}{c}75 \\
(12 / 16)\end{array}$ \\
\hline Mi-C & 15 & $2.8 \pm 0.4$ & $2096 \pm 695$ & $2.9 \pm 0.6$ & $2950 \pm 560$ & 0 & 0 \\
\hline Ni-Tx & 12 & $0.4 \pm 0.5$ & $178.5 \pm 67$ & $0.75 \pm 0.62$ & $198 \pm 69$ & & \\
\hline
\end{tabular}

Explanations: NA - Not applicable. * Cows were treated with a single intramammary aqueous suspension of $300 \mathrm{mg}$ of enrofloxacin hydrochloride-dihydrate ( $\mathrm{pH} 5.5)$ per day, for 8 days.

these groups are presented in Table 4. No statistically significant differences in pharmacokinetic parameters were found between Mi-Tx and Ni-Tx cows. $\mathrm{C}_{\text {MAX }}$

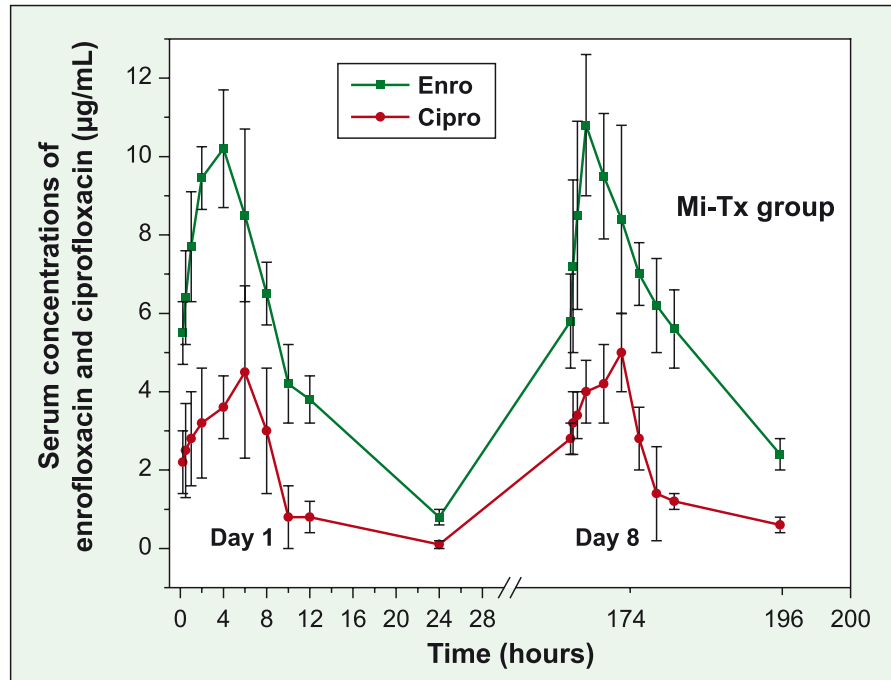

Fig. 1. Serum concentrations of enrofloxacin (enro) and ciprofloxacin (cipro) on day 1 and day 8 after intramammary administration of $300 \mathrm{mg}$ of enrofloxacin hydrochloride-dihydrate (pH 5.5) in cows with mastitis caused by coagulase-negative Staphylococcus aureus (Mi-Tx group) values at days 1 and 8 were not statistically different in mastitisinfected and healthy cows (ranging from 9.4 to $10.7 \mu \mathrm{g} / \mathrm{mL})$ $(\mathrm{P}>0.05)$. Yet, AUMC values increased by $56 \%$ in healthy cows from day 1 to day 8 (from 855 to $1337 \mu \mathrm{g}$ / $\left.\mathrm{mL} \cdot \mathrm{h}^{2}\right)$ and by $104 \%$ in mastitis-infected cows in the same period (from 783 to $1613 \mu \mathrm{g}$ / $\mathrm{mL} \cdot \mathrm{h}^{2}$ ), being the difference statistically significant $(\mathrm{P}<0.05)$. Levels in milk did not show significant differences between healthy and mastitis-infected cows,

Tab. 4. Serum pharmacokinetic parameters for enrofloxacin and ciprofloxacin in cows treated with a single intramammary aqueous suspension of $300 \mathrm{mg}$ of enrofloxacin hydrochloride-dihydrate. Cows were grouped as non-infected, enro-C-treated (Ni-Tx) and Staphylococcus aureus-infected, enro-C-treated (Mi-Tx group)

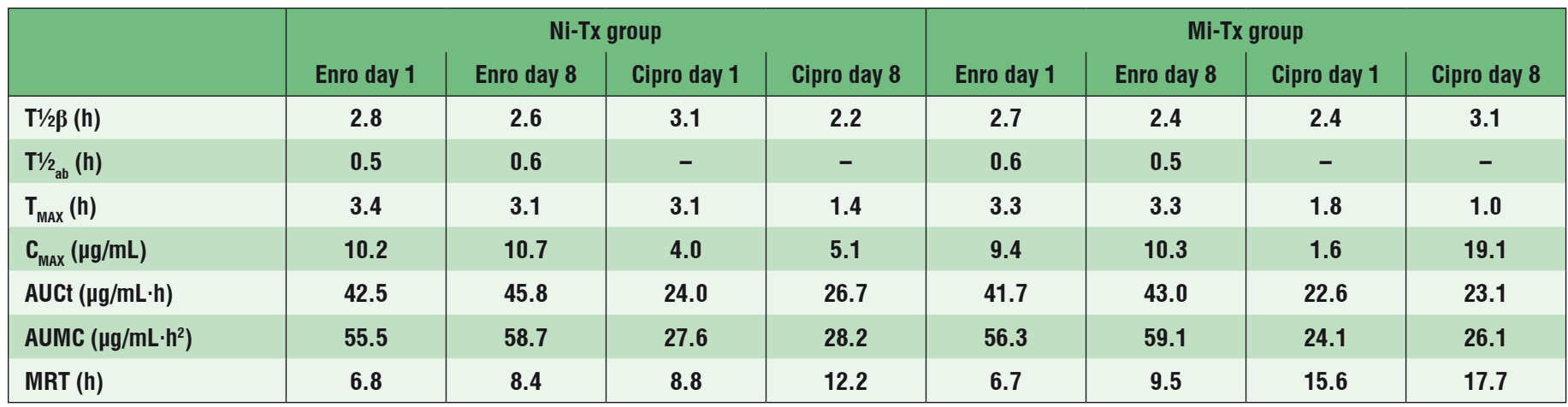

Explanations: $\mathrm{n}=8$ cows/group; $\mathrm{T}^{1} / 2_{\mathrm{ab}}$ - absorption half-life; $\mathrm{T}^{1} \mathrm{2} \beta$ - elimination half-life; $\mathrm{C}_{\mathrm{MAx}}-$ maximum serum concentration; $\mathrm{T}_{\mathrm{MAX}}$ - time to achieve $\mathrm{C}_{\mathrm{MAX}}$; $\mathrm{AUC}$ - area under the curve by the trapezoidal method; AUMC - under the moment curve from zero to $\infty$ with extrapolation of the terminal phase; MRT - mean residence time. Considering TTOST analysis, the null hypothesis of differences between day 1 and 8 was rejected for the same analyte. 
Tab. 5. Mean \pm SD milk concentrations of enrofloxacin and ciprofloxacin $(\mu \mathrm{g} / \mathrm{mL})$ after daily intramammary treatment of enrofloxacin hydrochloride-dihydrate for 8 days, at a dose of $300 \mathrm{mg} /$ quarter $(1.5 \%$ suspension, pH 5.5). Concentrations were determined in milk from the treated quarter only. Cows were grouped as non-infected, enro-C-treated (Ni-Tx), and Staphylococcus aureus-infected, enro-C-treated (Mi-Tx group)

\begin{tabular}{|c|c|c|c|c|c|c|c|c|c|}
\hline \multirow{2}{*}{ Day } & \multirow{2}{*}{$\begin{array}{l}\text { Hours after } \\
\text { treatment }\end{array}$} & \multicolumn{2}{|c|}{ Enro Mi-Tx group } & \multicolumn{2}{|c|}{ Cipro Mi-Tx group } & \multicolumn{2}{|c|}{ Enro Ni-Tx group } & \multicolumn{2}{|c|}{ Cipro Ni-Tx group } \\
\hline & & $\overline{\mathbf{x}}$ & \pm SD & $\overline{\mathbf{x}}$ & \pm SD & $\overline{\mathbf{x}}$ & \pm SD & $\overline{\mathbf{x}}$ & \pm SD \\
\hline \multirow{3}{*}{1} & 2 & 10.4 & 2.5 & 2.3 & 0.8 & 11.0 & 3.2 & 3.2 & 1.2 \\
\hline & 8 & 19.8 & 2.8 & 4.9 & 1.2 & 18.5 & 2.5 & 5.2 & 2.2 \\
\hline & 24 & 3.1 & 1.2 & 0.8 & 1.0 & 4.5 & 3.4 & 1.4 & 2.0 \\
\hline \multirow{3}{*}{8} & 2 & 11.4 & 3.0 & 3.5 & 1.4 & 14.0 & 2.8 & 3.8 & 1.6 \\
\hline & 8 & 20.2 & 3.4 & 5.6 & 0.8 & 22.0 & 1.2 & 5.9 & 1.8 \\
\hline & 24 & 4.2 & 1.2 & 1.6 & 1.6 & 5.2 & 0.8 & 2.0 & 0.8 \\
\hline
\end{tabular}

Explanations: $\mathrm{n}=8$ cows/group. No statistically significant differences were observed, comparing either enrofloxacin columns or ciprofloxacin columns $(1-\beta=0.83$, GPower 3.1.5)

with peak concentrations of $18.5-19.8 \mu \mathrm{g} / \mathrm{mL}$ on day 1 to $20.2-22 \mu \mathrm{g} / \mathrm{mL}$ on day 8 . Figure 3 and Table 5 show mean \pm SD enrofloxacin and ciprofloxacin milk concentrations on days 1 and 8 after treatment.

The physicochemical characteristics of enro-C include higher water solubility than that of the parent molecule (19). Yet, this feature was not sufficient to make it possible to prepare a solution rather than a suspension of $300 \mathrm{mg}$ of enro-C in $20 \mathrm{~mL}$. Hence, the pharmaceutical preparation was conceived as a stable suspension with a particle size smaller than $0.22 \mu \mathrm{m}$. Nevertheless, the higher water solubility of enro-C and particle size achieved in the experimental suspension, may have accounted for the rapid absorption phase observed $\left(\mathrm{T}^{1} / 2_{\mathrm{ab}}=0.5-0.6 \mathrm{~h}\right)$, which then resulted in a distinctly high $\mathrm{C}_{\mathrm{MAX}}$. The total dose administered was $300 \mathrm{mg}$, and this is only a fraction of the standard dose used in pharmacokinetic studies $(5 \mathrm{mg} / \mathrm{kg}$ i.e., approximately $3,000 \mathrm{mg} / \mathrm{cow}$ weighing $600 \mathrm{~kg}$ ). As no previous reference to a dose through the mammary route is available in the literature, a relatively high intramammary dose was chosen in an attempt to comply with high concentrations of enrofloxacin at this target site. In agreement with absorption, elimination half life $\left(\mathrm{T}^{1 / 2} \beta\right)$ ranged from 2.4 to $2.8 \mathrm{~h}$, a shorter value than previously reported for the standard preparation of enrofloxacin (approximately $6 \mathrm{~h}$ ) (14).

It is interesting that AUMC was not noticeably increased at day 8 of medication compared to day 1 (approximately 10-11\%). This parameter is in agreement with MRT values found in this study (from 6.8 to 9.5 for enrofloxacin and from 8.8 to 17.7 for ciprofloxacin), which are slightly faster than previously reported ones $(14,16)$. Intramuscular administration of a standard preparation of enrofloxacin at a dose of $5 \mathrm{mg} / \mathrm{kg}$ results in a MRT of $7.8 \mathrm{~h}$ (31). Additionally, considering that AUMC is used for assessing the extent of the distribution of a drug at steady state, the referred lack of substantial increment from day 1 to day 8 suggests that a good distribution outside the central compartment occurs on days both 1 and 8 . In fact, a certain amount of reentrance into the mammary gland may be

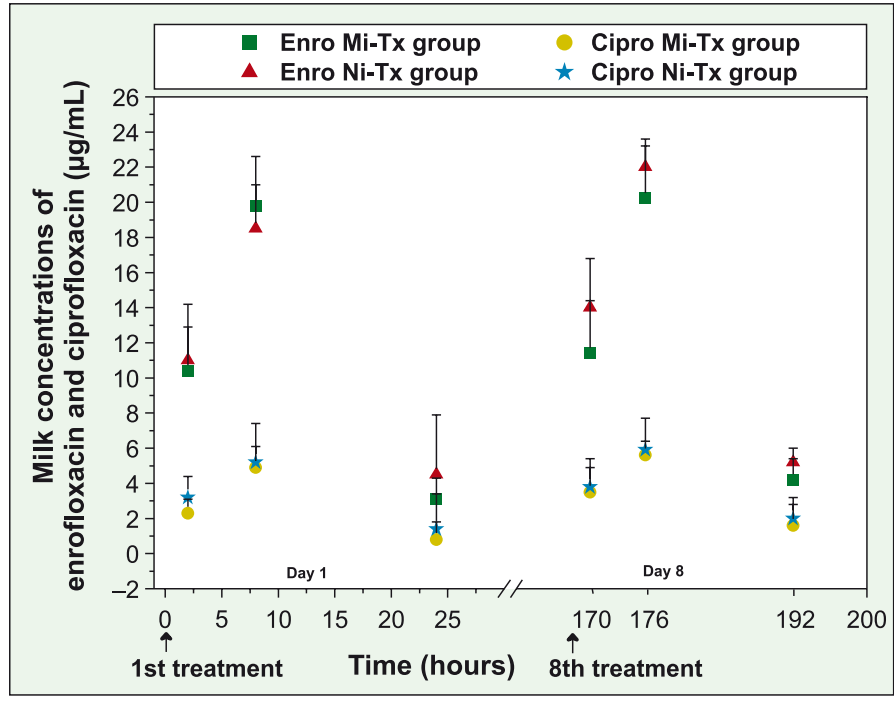

Fig. 3. Mean \pm SD milk concentrations of enrofloxacin (enro) and ciprofloxacin (cipro) on days 1 and 8 after daily intramammary treatment with $300 \mathrm{mg}$ of enrofloxacin hydrochloride-dihydrate ( $\mathrm{pH}$ 5.5) for 8 days. Treatments were applied to either Staphylococcus aureus-infected quarters (Mi-Tx group) or healthy ones (Ni-Tx group)

occurring, considering that the peak level in milk was augmented from $19.8 \mu \mathrm{g} / \mathrm{mL}$ on day 1 , to $22 \mu \mathrm{g} / \mathrm{mL}$ on day 8 . However this difference is not statistically significant, suggesting a first-order elimination kinetics of enrofloxacin through milk. In Figure 3 it is possible to observe that concentrations of enrofloxacin in milk after $24 \mathrm{~h}$ are approximately $3 \mu \mathrm{g} / \mathrm{mL}$ in MI-Tx cows and $4.5 \mu \mathrm{g} / \mathrm{mL}$ in Ni-Tx cows. In spite of enrofloxacin being a switterion molecule (30), the slight changes that occur in mammary tissue and fluids may be part of the explanation for this difference, as healthy tissue is more acidic than infected one. The same seems to apply to ciprofloxacin. Again, statistically significant differences were not obtained, which is consistent with the proposal of a first-order elimination kinetics. This observation requires confirmation with formal drugresidue depletion studies. For example, this study was carried out in F1 (50\% Holstein-50\% Zebu) cattle, and these animals behave in a more unpredictable and wayward manner than Holstein cows, making 
it difficult to have a more constant milk production. Also, the cows in this study lived in a tropical environment with outstanding variation in weather conditions and consequently in their drinking and eating habits. Nevertheless, a relevant issue that can be stressed in these data is that very large concentrations of enrofloxacin and ciprofloxacin are obtained, even $24 \mathrm{~h}$ after the intramammary administration of enro-C. Furthermore, the added antibacterial contributions of enrofloxacin and ciprofloxacin should result in a considerably higher antibacterial activity than the sum of their independent antibacterial effects $(18,26)$. This is particularly important, considering that only 2 to $3 \mu \mathrm{g} / \mathrm{mL}$ of enrofloxacin are found in milk after a standard dose of enrofloxacin, injected $\operatorname{IM}(13,14)$, and that cow's polymorphism can be a clinically relevant factor affecting the concentrations of enrofloxacin and ciprofloxacin in milk after parenteral administration of the drug (23).

It has been stated that the use of enrofloxacin requires specific plasma pharmacokinetic/pharmacodynamic (PK/PD) ratios to optimize clinical efficacy i.e., $\mathrm{C}_{\mathrm{MAX}}$ should be 10-12 times the value of the minimal inhibitory concentration (MIC), and the ratio AUCt/MIC should be equal to or higher than 125 (31). Considering that the $S$. aureus breakpoint for enrofloxacin is $0.25 \mu \mathrm{g} / \mathrm{mL}(8,21,26)$, the usually obtained concentrations of enrofloxacin and ciprofloxacin after the IM administration of enrofloxacin $(5 \mathrm{mg} / \mathrm{kg})$ would seem sufficient for clinical efficacy $(18,26)$. However, if higher milk concentrations are sought, such as in the case of enrofloxacin, a concentration-dependent antibacterial drug (2), intramammary administration of enro- $\mathrm{C}$ can prove useful. Taking only serum concentrations of enrofloxacin on day 1 in this study and 0.25 $\mu \mathrm{g} / \mathrm{mL}$ as the breakpoint for $S$. aureus, $\mathrm{PK} / \mathrm{PD}$ ratios would be: $\mathrm{AUCt} / \mathrm{MIC}=170$ and $\mathrm{C}_{\mathrm{MAX}} / \mathrm{MIC}>40$. If the maximum concentration of enrofloxacin obtained for milk $8 \mathrm{~h}$ after a single $300 \mathrm{mg} /$ gland dose is considered $(19.8 \mu \mathrm{g} / \mathrm{mL})$, the $\mathrm{C}_{\mathrm{MAX} \text { in milk }} / \mathrm{MIC}$ ratio would be 79. This latter ratio points to a clear advantage of intramammary administration of enro-C over the IM administration of enrofloxacin. Furthermore, the direct $\mathrm{C}_{\mathrm{MAX} \text { in milk }} / \mathrm{MIC}$ ratio of enrofloxacin and ciprofloxacin based on concentrations as obtained by HPLC may underestimate their combined antibacterial activity in vivo. In this study, the mean production of ciprofloxacin was $30 \%$ of the actual concentration of enrofloxacin in both mastitis-affected and healthy cows, increasing to $38 \%$ in the last sample taken $24 \mathrm{~h}$ after administration of enro-C. These values are lower than previously reported data for cows (59\%) (26). Different routes of administration and doses used in these studies, as well as cow breeds used, and a shorter elimination half-life found for enro-C in this study, may account for these discrepancies.

There is no clear explanation why $\mathrm{C}_{\mathrm{MAX}}$ obtained in this study was much higher than the corresponding values found in other studies after the administration of enrofloxacin through the IM route. A rapid absorption of enro-C through the mammary tissue can be advanced. This has been shown for florfenicol in lactating cows, with a three-fold increment in $\mathrm{C}_{\mathrm{MAX}}$ values (from 2.3 to $6.9 \mu \mathrm{g} / \mathrm{mL}$ ) (27). Also, higher $\mathrm{C}_{\mathrm{MAX}}$ values for enro-C have been shown after oral administration in broiler chickens (12) and after IM administration in hamsters (6). Enro-C can be described as a polymorphic enrofloxacin, and it is not rare to obtain better pharmacokinetics with a re-crystallized polymorph of an active principle $(7,26)$; for example: rifaximin- $\alpha$, a crystal polymorph, is much more bioavailable than the parent molecule (5). The higher water solubility of enro-C compared to standard enrofloxacin, and the manner in which nanoparticles are obtained in the referred preparation, may also be part of the explanation.

The most insidious and challenging etiology causing bovine mastitis is Staphylococcus aureus $(3,8,11$, 26). The more than 50 species and subspecies of this pathogen are usually divided into coagulase-positive and coagulase-negative $S$. aureus, the former being more virulent and prone to develop bacterial resistance $(3,8)$. These bacteria colonize many environments and make part of the cutaneous and mucosal flora in domestic animals and humans. S. aureus adheres to mammary epithelial cells, endothelial cells, and fibroblasts. These bacteria often enter the cytoplasm, escaping phagosomes and remaining in vacuoles, a process that facilitates apoptosis (11). Attempts to cure herds with this type of mastitis are a high economic investment with a low success rate $(22,29,30)$. Thus, although concentrations of enrofloxacin obtained in this study seem effective for treating mastitis caused by coagulase-negative Staphylococcus aureus, further evaluation is needed to determine whether such a long treatment protocol is economically viable and whether treatment with parenteral enrofloxacin has a comparable clinical efficacy. Maintaining the sample size for pharmacokinetics analysis, impeded this latter comparison.

Novel approaches have been proposed to improve the prognosis of $S$. aureus mastitis i.e., the extended therapy with multiple infusions of pirlimycin (9) ceftiofur (22) or cefquinome (29). However, to the best of our knowledge there has been no attempt to treat $S$. aureus mastitis with enrofloxacin, either by the parenteral route or by the intramammary one. Among the reasons to avoid this latter route is the high $\mathrm{pH}$ of pharmaceutical preparations (10.4-11), usually achieved by adding $\mathrm{KOH}$ as vehicle in most available preparations (28). Clearly, this makes intramammary administration unwise. In contrast, the $\mathrm{pH}$ of the $1.5 \%$ enro-C suspension used in this trial was 5.5, and it proved to be non-irritant to the mammary gland as assessed by direct clinical inspection, herein and in a previous study (17). Nevertheless, additional studies are required to validate this observation. The $75 \%$ 
efficacy with a daily use of intramammary enro-C (300 $\mathrm{mg} /$ quarter/day) for 8 days ranks among the best results found in the formal literature, particularly considering that cows included in this trial were old (5-7 years), and tissue damage must have already been well established (3). While the main objective of this study was to assess serum and milk enro- $\mathrm{C}$ concentrations after intramammary administration, a natural outbreak of mastitis due to coagulase-negative $S$. aureus allowed us to quantify treatment efficacy. Hence, any comparison with other studies in larger herds and different clinical settings should be treated with caution. For example, this trial was conducted in a tropical area with dualpurpose cattle. Nevertheless, it is worth emphasizing that these infections are in most cases refractory to routine intramammary antimicrobial therapy and tend to spread quickly, particularly in dairies with poor milking protocols (3).

Further studies are required before this antibacterial drug can be used in clinical practice, such as studies of potential toxicity of the chosen dose of intramammary enro-C to mammary cells and epidemiological pertinence of incorporating enrofloxacin as intramammary medication in terms of bacterial resistance. Regulations on the use of antibacterial drugs vary with each country. Thus, at this stage, a universal, epidemiological point of view on the use of enro-C is not possible. However, it is worth pointing out that the high concentrations of enrofloxacin and ciprofloxacin obtained in milk with enro-C are likely to reach the so-called mutant prevention concentrations $(20,23)$, thus reducing drastically the emergence of resistant strains. Also, if a pharmaceutical preparation of enro-C becomes available, time to reach the maximum residue limit in milk (MRL) must be established.

\section{References}

1. Artursson K., Nilsson-Ost M., Persson W. K.: An improved method to culture Staphylococcus aureus from bovine milk. J. Dairy Sci. 2009, 93, 1534-1538.

2. Attili A. R., Preziuso S., Ngu Ngwa V., Cantalamessa A., Moriconi M., Cuteri V.: Clinical evaluation of the use of enrofloxacin against Staphylococcus aureus clinical mastitis in sheep. Small Rum. Res. 2016, 136, 72-77.

3. Barkema H. W., Schukken Y. H., Zadoks R. N.: The role of cow, pathogen, and treatment regimen in the therapeutic success of bovine Staphylococcus aureus mastitis. J. Dairy Sci. 2006, 89, 1877-1895

4. Bennett R. W., Lancette G. A.: FDA's Bacteriological Analytical Manual. Bacteriological Analytical Manual Chapter 12 Staphylococcus aureus. USDA/ FSIS Microbiological Laboratory Guidebook, 3rd Edition, 2001

5. Blandizzi C., Viscomi G. C., Scarpignato C.: Impact of crystal polymorphism on the systemic bioavailability of rifaximin, an antibiotic acting locally in the gastrointestinal tract, in healthy volunteers. J. Drug Design Develop Ther. 2015, 9, 1-11.

6. Carrascosa A., De-la-Peña A., Gutierrez L., Sumano H.: Serum pharmacokinetics and tissue concentrations of a newrecrystallized enrofloxacin hydrochloride-dihydrate in hamsters. Turk. J. Vet. Anim. Sci. 2015, 39, 661 $-667$.

7. Censi R., Di Martino P.: Polymorph impact on the bioavailability and stability of poorly soluble drugs. Molecules 2015, 20, 18759-18776.

8. Chandrasekaran D., Venkatesan P., Tirumurugaan K. G., Nambi A. P., Thirunavukkarasu P. S., Kumanan K., Vairamuthu S., Ramesh S.: Pattern of antibiotic resistant mastitis in dairy cows. Vet. Word 2014, 6, 389-394.

9. Deluyker H. A., Van Oye S. N., Boucher J. F.: Factors affecting cure and somatic cell count after pirlimycin treatment of subclinical mastitis in lactating cows. J. Dairy Sci. 2005, 88, 604-614.
10. Fang G., Vikerpuur M.: Potency of antibacterial drugs in milk as analysed by $\beta$-glucuronidase-base-fluorometry. J. Vet. Pharmacol. Ther. 1995, 18, 422-428.

11. Foster T. J.: Immune evasion by staphylococci. Nature Rev. Microbiol. 2005, 3, 948-958.

12. Gutierrez L., Miranda-Calderon J. E., Garcia-Gutierrez P., Sumano H. Physicochemical characterization and pharmacokinetics in broiler chickens of a new recrystallized enrofloxacin hydrochloride dihydrate. J. Vet. Pharmacol. Ther. 2014, 38, 183-189.

13. Idowu O. R., Peggins J. O.: Simple, rapid determination of enrofloxacin and ciprofloxacin in bovine milk and plasma by high-performance liquid chromatography with fluorescence detection. J. Pharm. Biomed. Analysis 2004, 35, 143-153.

14. Kaartinen L., Salonen M., Alli L., Pyorala S.: Phamacokinetics of enrofloxacin after single intravenous, intramuscular and subcutaneous injections in lactating cows. J. Vet. Pharmacol. Ther. 1995, 18, 357-362.

15. Korudjiski N., Chaleva E., Gurgulova K., Galabinova T.: Intramammary products for treatment of subclinical mastitis in cows. CR Acad bulgar Sci. 2009, 62, 1039-1046.

16. Kwon Y.: Handbook of Essential Pharmacokinetics, Pharmacodynamics and Drug Metabolism for Industrial Scientists. Bioneer Life Science San Diego Cal. 2001.

17. Martinez-Cortés I.: Farmacocinética sérica y diffusion a leche en bovinos sanos de una enrfoloxacina recristalizada. Thesis Master in Science. Universidad Nacional Autónoma de México. Facultad de Medicina Veterinaria y Zootecnia. Mexico City 2013.

18. McKellar Q., Gibson I., Monteiro A., Bregante M.: Pharmacokinetics of enrofloxacin and danofloxacin in plasma, inflammatory exudate, and bronchial secretions of calves following subcutaneous administration. Antimicrob Agents Chemother. 1991, 43, 1988-1992.

19. Miranda-Calderón J. E., Gutierrez L., Flores-Alamo M., García-Gutierrez P., Sumano $H$.: Enrofloxacine hydrochloride dihydrate. Acta Crystallograph. sec. E 2014, 70, 468-469

20. Nedbalcová K., Nechvátalová K., KučerováZ.: Determination of the minimum inhibitory concentration (MIC) and mutant prevention concentration (MPC) of selected antimicrobials in bovine and swine Pasteurella multocida, Escherichia coli, and Staphylococcus aureus isolates. Acta Vet. Brno 2015, 84, 83-89.

21. Nunes S. F., Bexiga R., Cavaco L. M., Vilela C. L.: Antimicrobial susceptibility of Portuguese isolates of Staphylococcus aureus and Staphylococcus epidermidis in subclinical bovine mastitis. J. Dairy Sci. 2007, 90, 3242-3246.

22. Oliver S. P., Gillespie B. E., Headrick S. J., Moorehead H., Lunn P., Dowlen H. H., Johnson D. L., Lama K. C., Chester S. T., Moseley W. M.: Efficacy of extended ceftiofur intramammary therapy for treatment of subclinical mastitis in lactating dairy cows. J. Dairy Sci. 2004, 87, 2393-2400.

23. Otero J. A., García-Mateos D., de la Fuente A., Prieto J. G., Álvarez A. I., Merino $G$.: Effect of bovine ABCG2 Y581S polymorphism on concentrations in milk of enrofloxacin and its active metabolite ciprofloxacin. J. Dairy Sci. 2016, 99, 5731-5738

24. Ramalingam B., Sidhu P. K., Kaur G., Venkatachalam D., Rampal S.: Mutan prevention concentration, pharmacokinetic-pharmacodynamic integration, and modeling of enrofloxacin data established in diseased buffalo calves. J. Vet. Pharmacol. Ther. 2015, 38, 529-536.

25. Raza K., Kumar P., Ratan S., Malik R., Arora S.: Polymorphism: the phenomenon affecting the performance of drugs. SOJ Pharm. Pharmaceut. Sci. 2015 $1,1-10$.

26. Russi N. B., Bantar C., Calvinho L. F.: Antimicrobial susceptibility of Staphylococcus aureus causing bovine mastitis in Argentine dairy herds. Rev. Arge Microbiola 2008, 40, 116-119.

27. Soback S., Paape M. J., Filep R., Varma K. J.: Florfenicol pharmacokinetics in lactating cows after intravenous, intramuscular and intramammary administration. J. Vet. Pharmacol. Ther. 1995, 18, 413-417.

28. Sumano H., Ocampo L.: Compositional analysis surveillance of eleven brands of enrofloxacin including Baytril® for veterinary use. J. Vet. Med. (A) 1995, 42, 669-673.

29. Swinkels J. M., Cox P., Schukken Y. H., Lam T. J.: Efficacy of extended cefquinome treatment of clinical Staphylococcus aureus mastitis. J. Dairy Sci. 2013, 96, 4983-4992

30. Taponen S., Jantunen A., Pyorala E., Pyorala S.: Efficacy of targeted 5-day combined parenteral and intramammary treatment of clinical mastitis caused by penicillin-susceptible or penicillin-resistant Staphylococcus aureus. Acta Vet. Scand. 2003, 44, 53-62.

31. Wright D. H., Brown G. H., Peterson M. L., Rotschafer J. C.: Application of fluoroquinolone pharmacodynamics. J. Antimicrob. Chemother. 2000, 46, 668-669.

Corresponding author: Hector Sumano, DVM, MD, PhD; Departamento de Fisiología y Farmacología, Facultad de Medicina Veterinaria y Zootecnia. Universidad Nacional Autónoma de México. Av. Universidad 3000, Coyoacán Mexico City, 04510, México; e-mail: sumano@unam.mx 